\title{
Using a Cognitive-Behavioral Approach to Reduce Aggressive Responses in an Adolescent with Borderline Intelligence
}

\section{Harum Saraswati ${ }^{\mathrm{a}}$ and Rini Hildayani ${ }^{\mathrm{b}}$}

${ }^{a}$ Clinical Child Psychology Department, Faculty of Psychology, Universitas Indonesia, Depok, Indonesia; ${ }^{b}$ Clinical Child Psychology Department, Faculty of Psychology, Universitas Indonesia, Depok, Indonesia

*Corresponding author:

Rini Hildayani

Department of Developmental Psychology, Faculty of Psychology, Universitas Indonesia Jl. Lkr. Kampus Raya, Depok, Jawa Barat Indonesia, 16424

Tel.: +62 217270004

Email address: rini.hildayani@gmail.com 


\title{
Using a Cognitive-Behavioral Approach to Reduce Aggressive Responses in an Adolescent with Borderline Intelligence
}

\begin{abstract}
This research investigated the reduction of aggressive responses in an adolescent with borderline intelligence through the implementation of anger management intervention using a cognitive behavioral approach. The participant in this research was a thirteen-year-old girl who has difficulty in managing her anger which manifested in aggressive behavior. This research refers to anger management using a cognitive behavioral approach for people with intellectual disabilities, as developed by Taylor and Novaco (2005). Measurements were taken before and after the intervention through self-report measures, such as the Anger Expression Scale for Children (AESC) from Steele, Legerski, Nelson, and Phipps (2009); the anger thermometer from Taylor and Novaco (2005); and the Child Behavior Checklist (CBCL) from Achenbach (1991). The results of this study indicated that anger management using a cognitive behavioral approach can reduce aggressive responses in an adolescent with borderline intelligence. These results were seen from changes in the participant's expression of anger before and after the intervention. Before the intervention, the participant expressed her anger through yelling, uttering harsh words, hitting, kicking, throwing, or destroying things. After the intervention, the participant was more able to control her anger and displayed fewer aggressive responses. Yelling and uttering harsh words rarely appeared.
\end{abstract}

Keywords: aggressive, anger treatment, borderline, cognitive-behavioral, angry, adolescent.

\section{Introduction}

This Emotions help individuals adapt to their environment, but individuals need to control their emotions so they can adapt appropriately (Izard, Ackerman \& Saarni et al.; in Kail, 2012; Bhave \& Saini, 2009). In general, there are two kinds of emotions: positive emotions and negative emotions (Faupel, Herrick, \& Sharp, 2011). One form of positive emotion is happiness, while one form of negative emotion is anger (Shaffer, 2009). Although anger is a negative emotion, it is not always a sign of emotional instability, but is naturally experienced by every individual; children, adolescents, and adults (Golden, 2003). However, anger can be a problem if the frequency or intensity increases excessively, and endangers oneself or others. This prevents people from achieving their goals (Westbrook, Kennerley, \& Krik, 2007).

Bhave and Saini (2009) revealed that throughout the stages of human development, individuals must manage their anger, although for some it presents a challenge. One group of individuals who have difficulty controlling anger is teenagers. Teenagers are the group most often referred for psychological help caused by anger problems, as well as children (Abikoff \& Klein; in Valizadeh, Davaji \& Nikamal, 2010). Teens have unstable emotions, so they often display explosive anger when facing unpleasant situations, which are expressed in the form of aggressive behavior. This indicates the ability to regulate emotions in adolescents is not well developed. As they get older, teenagers are expected to be able to regulate emotions increasingly in line with social demands (Papalia, Old, \& Feldman, 2007). 
The ability to manage anger requires a variety of resources, including the cognitive and behavioral capacities of adolescents (Folkman \& Lazarus; in Jankowska, 2016). Adolescents who have below average intelligence have limited capacities, and therefore tend to experience more difficulty managing their anger. Adolescents with below average intelligence, especially borderline intelligence, have intellectual limitations and poor awareness of themselves. Most rarely develop the ability to deal with difficult emotions, such as anger (van Nieuwenhuijzen \& Vriens; in Jankowska, 2016).

Adolescents with borderline intelligence have difficulty managing anger because they often develop a biased perspective on a situation, by assessing the situation more negatively and perceiving the intentions of others as a threat (van Nieuwenhuijzen \& Vriens; Pereira; in Jankowska, 2016). Inaccuracy in processing information and lack of ability to solve a problem effectively results in more aggressive responses in those with borderline intelligence (van Nieuwenhuijzen, et al.; in Jankowska, 2016).

The case in this study was a girl with the initial $\mathrm{N}$, the first child of two siblings. $\mathrm{N}$ was 13 years old and in the second grade of junior high school. $\mathrm{N}$ had undergone a series of psychological examinations conducted by researchers. Based on the results of the intelligence examination conducted, $\mathrm{N}$ was classified as borderline (IQ $=75$, Wechsler scale). The intellectual ability of $\mathrm{N}$ was far below the average for their age. $\mathrm{N}$ has a low ability to understand and solve social problems, so she has difficulty acting in accordance with the values and norms that apply in social situations. In addition, the examination also revealed that N's problem solving abilities were poor.

Based on the Child Behavior Checklist (CBCL) measurements, $\mathrm{N}$ had a tendency to behave aggressively which was classified as a clinical problem. $\mathrm{N}$ often quarreled, was stubborn, and often angry when facing unpleasant situations. In addition, when angry, $\mathrm{N}$ sometimes damaged the items around her by throwing or kicking them. $\mathrm{N}$ also yelled and said harsh words, and attacked others by hitting.

$\mathrm{N}$ was often angry about things she deemed unpleasant or disturbing. When angry $\mathrm{N}$ behaved aggressively, either verbally with harsh words (such as shouting "anjing" or "monyet") or physically, by hitting, pushing, kicking and throwing things. $\mathrm{N}$ could not control her anger, especially when she heard her grandmother shouting. $\mathrm{N}$ became angry with her grandmother and expressed it by shouting harsh words, hitting, throwing things (for example: plastic cups or TV remote), and throwing water.

$\mathrm{N}$ also often became angry with her sister, for example when fighting over a show on TV or when her sister borrowed her belongings. $\mathrm{N}$ was disturbed if the activity she was doing was interrupted by her younger brother, when she would shout, push, or beat her brother lightly. In addition to her grandmother and younger siblings, $\mathrm{N}$ also often expressed her anger toward her mother; for example, when asked to study by the mother, or vice versa; when asking her mother to accompany her studies when the mother was doing housework. $\mathrm{N}$ also became angry when 
mother did not grant her wishes. When angry with her mother, $\mathrm{N}$ destroyed her mother's favorite item. According to her mother, $\mathrm{N}$ never apologized after being angry.

While at school, $\mathrm{N}$ also displayed angry attitudes toward her friend. Feeling annoyed, $\mathrm{N}$ scolded her friend in front of her other friends. In addition, $\mathrm{N}$ was also involved in a fight because she was ridiculed by one of her friends, so she was summoned by a teacher for Counseling Guidance (BK). Even so, N's response when fighting in school did not comprise physical action, but only shouting harsh words. As a result of N's irritable attitude at school, not many children at school wanted to play with her.

$\mathrm{N}$ was more often triggered by anger when at home (especially toward her grandmother, younger siblings, and mother) compared to other places, such as school and tutoring. $\mathrm{N}$ could better resist the urge to take physical action when angry at school and during tutoring, because she did not want to be labeled "bad" by her friends. Meanwhile, $\mathrm{N}$ thought that her physical and verbal aggression at home were caused people's mistakes at home (grandmother, sister, and mother) who disturbed her.

Some interventions that can be used to overcome anger problems are social skills training, behavioral interventions, and cognitive behavioral interventions (Charlesworth, 2008; Bhave \& Saini, 2009; DiGiuseppe \& Tafrate; in Valizadeh, Davaji \& Nikamal, 2010). Some forms of social skills training include assertiveness training and problem solving (Charlesworth, 2008). In general, social skills training researchers have concluded that individuals can learn and apply new skills during training (Goldstein et al.; Edelstein \& Eisler; Eisler, Miller \& Hersen; in Bolanos, 1998). However, how far these skills can be generalized to other situations has not been clearly described (Bolanos, 1998). Similar views were conveyed by Deffenbacher, Oetting, and DiGiuseppe (2002), that a weakness of social skills training is it provides poor empirical evidence in support of the generalization of application and the external validity of the approach. In addition, social skills training does not address errors in thinking, or the individual's cognitive skills, but focuses on developing verbal and non-verbal skills that individuals need to initiate and maintain interpersonal relationships (Sudhir, 2015).

Behavioral interventions can also be used to overcome anger problems, through relaxation training and self-monitoring (Charlesworth, 2008). However, research conducted by Fernandez and Beck (2001), suggested that behavioral interventions using self-monitoring only do not monitor changes in the frequency, duration, and intensity of anger compared to other interventions, such as cognitive interventions. Miltenberger (2008) also said that the behavioral approach only changes behaviors that are overt (visible or observable by others) without changing a person's characteristics, so it is often considered an incomplete approach to solving problems related to individual emotional states. Emotions such as anger are covert behaviors that involve individuals' thinking, problem solving abilities, and planning abilities, so approaches that focus on overt behavior change are inappropriate (Miltenberger, 2008).

Another widely used and effective intervention for overcoming anger is the cognitive behavioral approach (Childre \& Rozman; Kassinove \& Tafrate; in Charlesworth, 2008). Interventions 
which use cognitive behavioral approaches not only focus only on behavioral changes, but also on cognitive skills that influence the formation of behavior.

Interventions that use a cognitive behavioral approach involve three main components that include cognitive, emotional (arousal), and behavioral areas (Taylor \& Novaco, 2005). Psychological examinations of $\mathrm{N}$ revealed that $\mathrm{N}$ had borderline intelligence. In fact, individuals with a borderline level of intelligence experience limitations in performing analytic tasks and lack self-awareness, or the capacity to think about themselves (Masi, Marcheschi, \& Pfanner, 1998). This would certainly affect N's ability to receive and process information given during interventions that use a cognitive behavioral approach.

Despite the obstacles encountered using such approaches with individuals with borderline intelligence, research in human development has suggested that therapy using a cognitive behavioral approach can still be used with such clients (Pence, Aldea, Sulkowski, \& Storch; in Jankowska, 2016). The strategy used must accommodate the specific needs of the client and be designed specifically for their limitations in cognitive capacity, language skills, and other resources (Jankowska, 2016). Thus the researchers have assumed that a cognitive behavioral intervention for individuals with borderline intelligence can be effective, including in N's case.

In N's case, this approach was acceptable because $\mathrm{N}$ had faulty thoughts which influenced her behavior. $\mathrm{N}$ thought that she could not control her emotions and considered the fault lay with those who were bothering her. Using a cognitive behavioral approach, researchers aimed to restructure N's thinking, to reduce her aggressive responses when she feels disturbed.

\section{Theoretical Review}

Borderline intelligence refers to intelligence levels or IQ scores that range from 71 to 84; one level is below the normal average but is not included in the category of intellectual disabilities (Karande, Kanchan, \& Kulkarni, 2008). Although cognitive functions that are below average give rise to intellectual limitations for individuals who experience them, not all individuals experience disruption or dysfunction in their life as a result of borderline intelligence.

Cognitively, a teenager should have reached the stage of formal operational development. However, adolescents with borderline level of intelligence usually only reach operational concrete stages at the age of 10 to 12 years, and rarely reach the formal operational stage (Masi, Marcheschi, \& Pfanner, 1998). Thus, adolescents with borderline intelligence levels will usually experience limitations in carrying out tasks that involve planning and analysis, and lack awareness of their own thinking processes (Masi, Marcheschi, \& Pfanner, 1998).

Teenagers with borderline intelligence also have difficulties with social information processing, emotional recognition, and perspective-taking (Bauminger, Schorr-Edelsztein, \& Morash; Ninivaggi; Van Nieuwenhuijzen et al.; in Jankowska, 2016). In stressful and confusing situations, adolescents with borderline intelligence often develop a biased perspective on a situation, by assessing it more negatively and perceiving the intentions of others as a threat (van 
Nieuwenhuijzen \& Vriens; Pereira; in Jankowska, 2016). Inaccuracy in processing information, and a lack of ability to solve problems effectively, result in adolescents with borderline intelligence expressing more aggression (van Nieuwenhuijzen, et al.; in Jankowska, 2016).

Some characteristics of adolescents with borderline intelligence include a low tolerance of frustration, easily triggered anger, and difficulty coping with emotional stress, which often leads them to be easily triggered when faced with situations that arouse their emotions; for example, when disturbed by others. What's more, adolescents with borderline intelligence display rigidity in cognitive function, such as the inability to modify a concept, and difficulty considering a problem from a different perspective (Masi, Marcheschi, \& Pfanner, 1998). Therefore, they are often unable to take the appropriate steps to remain socially acceptable when facing stressful or anger-provoking situations.

Anger is defined as an acute emotional reaction caused by various stimuli, such as threats, aggressiveness, detention or limitation, verbal assault, disappointment, or frustration (Chaplin; in Charlesworth 2008). Novaco (1975; in Blake \& Hamrin, 2007), Kassinove and Sukhodolsky (1995; in Blake \& Hamrin, 2007) define anger as an emotional state experienced by each individual that is a combination of physiological, cognitive, and behavioral reactions. Each of these aspects is interrelated and influences how individuals express their anger (Day et al., 2008). Changes in any of these three aspects can be observed in changes in the following characteristics (Charlesworth, 2008; Schiraldi \& Kerr, 2002; Novaco \& Howells; in Day et al., 2008):

1. Physical or physiological symptoms, such as blushing, increased heart rate or blood pressure, muscle tension, and adrenal flow;

2. Cognitive experiences, such as automatic thoughts, cognitive distortions or negative perceptions, and interpretations that deviate from the behavior of others; and

3. Behavioral reactions, including body language and facial expressions, such as clenching fists or frowning; as well as explosive physical and verbal actions such as shouting, yelling, kicking, and hitting.

When dealing with anger, each individual will express it in different ways (Faupel, Herrick, \& Sharp, 2011). Anger is a normal emotional reaction if it is expressed in an effective way, such as communicating feelings of anger while respecting others (Faupel, Herrick, \& Sharp, 2011). Normal anger functions as a warning of an approaching threat when needs are not met, and motivate one's self to avoid threats or meet needs that are not being fulfilled (Faupel, Herrick, \& Sharp, 2011).

However, anger can also be expressed ineffectively, causing problems (anger problems) which interfere with interpersonal relationships (Bhave \& Saini, 2009; Faupel, Herrick, \& Sharp, 2011). The effect of the ineffective and excessive expression of anger can have many negative consequences. Excessive anger can cause physical problems, such as headaches, hypertension, ulcers, asthma, heart disease, stroke, and diabetes; as well as psychological problems, such as anxiety, depression, lack of concentration, lack of confidence, helplessness, mood changes, and suicidal ideas (Bhave \& Saini, 2009). 
Handling anger problems is a challenging job for clinicians (Novaco \& Jarvis, 2002). The main problem that arises is 'dysregulation'; the lack of proper control over anger, such as anger triggers, angry expressions, and the effects of anger (Novaco \& Jarvis, 2002). Anger treatment is a form of individually tailored anger management. Anger treatment requires deeper involvement from clients; which is obtained through an examination and a program designed specifically to meet the client's needs. In addition, anger treatment also requires clinical coordination and supervision during its implementation. The aim of anger treatment is to improve self-regulation in the cognitive, arousal, and behavioral areas involved.

Since the 1980s, cognitive behavioral interventions have emerged and been widely accepted as approaches for overcoming anger problems (Day et al., 2008). Anger treatment using a cognitive behavioral approach assumes that anger depends on the individual's perceptions, hopes, and judgments of situations that provoke anger (Bhave \& Saini, 2009). Thus, anger treatment formulations that are arranged individually aim to help individuals modify or change their thoughts and beliefs, so that the anger resulting from their perceptions of situations that are considered threatening can be effectively addressed (Bhave \& Saini, 2009). In addition, anger treatment also aims to help individuals to control their responses when faced with situations that trigger anger (Taylor \& Novaco, 2005).

The main components of anger treatment using a cognitive behavioral approach are: (1) cognitive re-structuring of the focus of the client's attention, including the way the client thinks and sees a situation; (2) arousal reduction of provocative situations and impulsive reactions through regulating breathing, muscle relaxation, and the use of calming imagination; and (3) behavioral training skills to overcome situations that trigger constructive anger and solve problems (Taylor \& Novaco, 2005). These three components are modified through gradual exposure in the form of exercises simulating situations that trigger anger, using imagination and role playing with the help and direction of the therapist.

Anger treatment intervention programs that use a cognitive behavioral approach are one way to teach individuals how to cope with stressful situations that provoke anger, such as those experienced by teenagers with borderline intelligence, due to their difficulties in coping with situations that arouse negative emotions. The emphasis on the cognitive area means that individual with limited intellectual abilities will experience obstacles when participating in programs that involve a cognitive behavioral approach. The difficulties these individuals might experience are anticipated through prompt delivery or assistance during the program. If individuals experience difficulties in thinking, understanding the material, or finding alternative solutions to the problem, assistance is provided in the form of concrete examples; such as the use of images to explain the material, or giving advice on alternative solutions to problem solving to stimulate individuals to think further (Taylor \& Novaco, 2005).

\section{Methods}

This study used a single-case design $(\mathrm{N}=1)$, which is a design used to test an intervention on one individual. According Taylor and Novaco (2005), suitable interventions for individuals with 
anger problems are those that are individually tailored. Thus, a case-study design was used in this research to examine one individual in depth. In addition, the single-case design is often chosen by clinical experts as a way to combine research and practice with clients (Barker, et al., 2002).

The design of the intervention carried out in this study was a modification of the Cognitive Behavioral Anger Treatment design specially made by Taylor and Novaco (2005) for individuals with intellectual disabilities (ID) at mild-borderline to moderate level. The design compiled by Taylor and Novaco (2005) amounted to eighteen sessions consisting of two stages (six sessions at the preparation stage and twelve treatment sessions). In the manual, it is stated that therapists and clients can use it flexibly according to a client's needs. Thus, there are variations in the emphasis and speed of therapy performed with different clients, depending on the analysis and formulation of their anger problems (Taylor \& Novaco, 2005). Based on this, the researcher modified the intervention design and adjusted it to the needs of participant $(\mathrm{N})$, considering that $\mathrm{N}$ had a borderline level of intelligence, not ID. The interventions that have been modified were carried out over eleven sessions consisting of two stages (three sessions at the preparation stage and eight treatment sessions).

The intervention used three measuring instruments, namely the Anger Expression Scale for Children (AESC), the anger thermometer, and the Child Behavior Checklist (CBCL). AESC (Steele, Legerski, Nelson, \& Phipps, 2009) is a self-report Likert-type scale consisting of 26 items designed to assess anger in children aged 7 to 17 years. There are four dimensions assessed by the AESC: ten trait anger items (for example: "I get angry easily"), six anger expression items (for example: "I slam the door or stomp my foot"), four internalized anger items (example: "I harbor it alone"), and six anger control items (example: "I control my anger").

The anger thermometer (Taylor \& Novaco, 2005) is a self-rating method which requests participants to rate how much anger they feel when triggered. This intervention measures the intensity or strength of the child's anger. $\mathrm{N}$ will be asked to assess the intensity of her anger across four scales.

CBCL (Achenbach, 1991) is an inventory scale that has been standardized to measure problem behavior in children aged 4-18 years, based on the assessments of parents or other caregivers who know the child well. The CBCL consists of 115 statement items organized into three major groups of behavioral problems, internalizing problems (consisting of withdrawn behavior, somatic complaints, anxiety/depression), externalizing problems (consisting of delinquent behavior, aggressive behavior), and groups that do not include internalizing problems or externalizing problems (consisting of social problems, cognitive problems, attention problems). 


\section{Result}

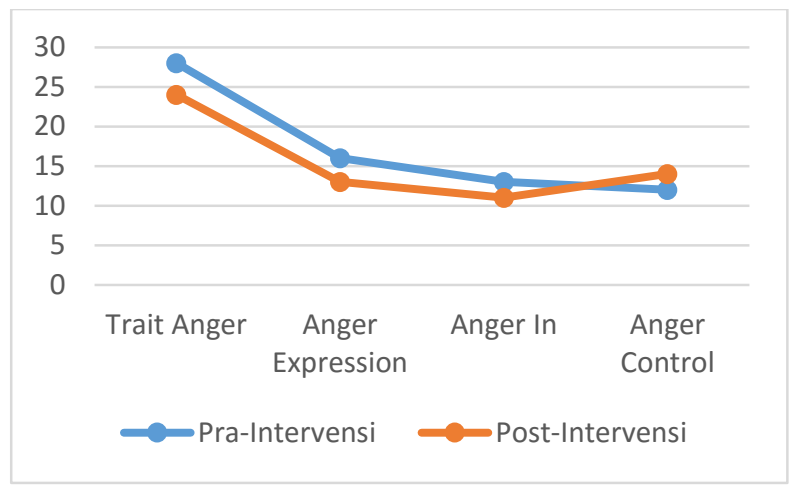

Fig. 1. Example of a figure AESC Score Before and After Intervention

The comparison of the AESC scores showed that after the anger treatment intervention program, N's assessment of her trait aspects of anger, anger expression, anger in, and anger control changed. Before the intervention, the trait anger score was above average, while after the intervention the score was below average. N's anger expression score before the intervention was above average, but after the intervention was below average. These decreasing scores indicated a decrease in the frequency of N's negative expression of anger. Meanwhile, N's anger internalization score before and after the intervention remained above average, although there was a decrease of 2 points. This indicated that $\mathrm{N}$ was still harmed by her anger, even though the frequency had begun to decline. N's anger control score before and after the intervention remained below average, although there was an increase of 2 points. This means that after the intervention, $\mathrm{N}$ tried to control her anger and remain calm.

Fig. 2. Comparison of Anger Thermometer Scores between Pre and Post Intervention

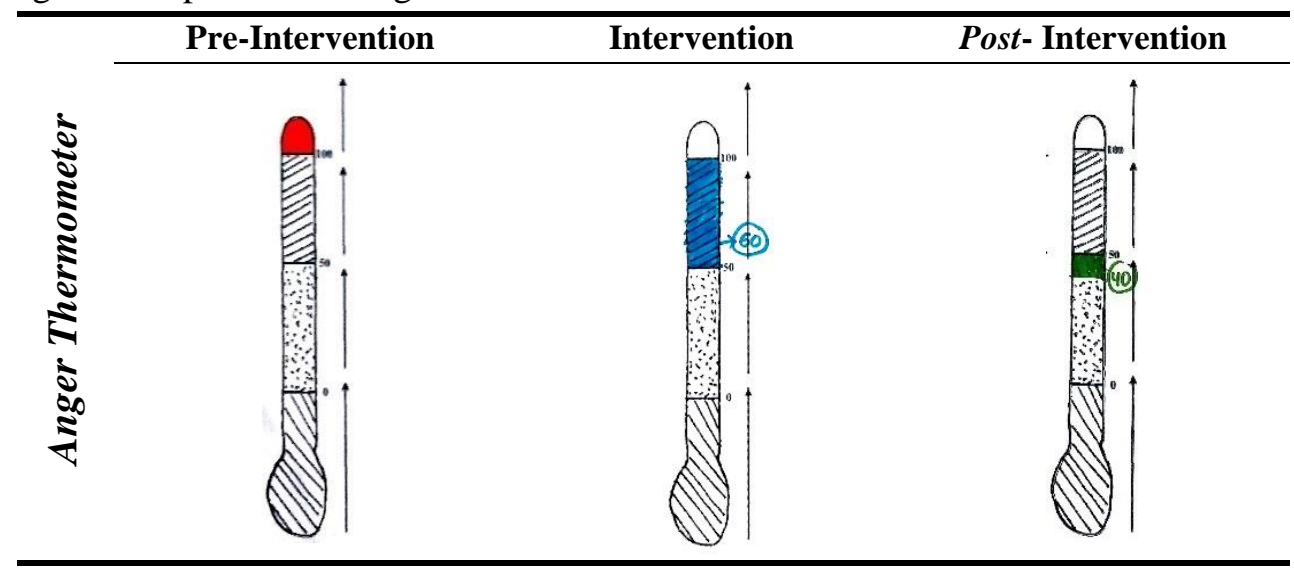

A comparison of N's anger thermometer ratings shows that after the anger treatment intervention N's anger intensity decreased. The pre-intervention scores were above 100 ('boiling point'). This score indicates that when $\mathrm{N}$ faced a situation that triggered her anger, she had no control over her behavior and could not think clearly. After the preparation stage (as many as three sessions) was conducted, the score fell to below 60. This score indicated that when $\mathrm{N}$ faced a situation that triggered her anger, she still experienced a level of anger that made her feel very tense or anxious. At this level, $\mathrm{N}$ still felt she had no control over her behavior. Meanwhile the post-intervention results showed a score of 40 . This score indicated 
that when $\mathrm{N}$ faced a situation that triggered her anger, she tried to relax and control her behavior even though she still often accidentally expressed anger negatively when her emotions peaked.

Table I. Comparison of CBCL Scores between Pre- and Post-Intervention

\begin{tabular}{|c|c|c|c|c|c|c|}
\hline & \multirow{2}{*}{ Aspek } & \multirow{2}{*}{$\begin{array}{l}\text { Batas } \\
\text { Klinis }\end{array}$} & \multicolumn{2}{|r|}{ Pra-Intervensi } & \multicolumn{2}{|r|}{ Post-Intervensi } \\
\hline & & & Skor & Keterangan & Skor & Keterangan \\
\hline \multirow{7}{*}{ 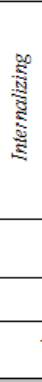 } & Withdrawn & 7 & 8 & $\begin{array}{c}\text { Borderline Clinical } \\
\text { Range }\end{array}$ & 4 & Normal Range \\
\hline & $\begin{array}{c}\text { Somatic } \\
\text { Complaints }\end{array}$ & 5 & 2 & Normal Range & 2 & Normal Range \\
\hline & Anxious/Depressed & 11 & 10 & Normal Range & 6 & Normal Range \\
\hline & Total & 13 & 19 & Clinical Range & 12 & Normal Range \\
\hline & Social Problems & 6 & 8 & $\begin{array}{c}\text { Borderline Clinical } \\
\text { Range }\end{array}$ & 5 & Normal Range \\
\hline & Thought Problems & 2 & 1 & Normal Range & 1 & Normal Range \\
\hline & Attention Problems & 8 & 10 & $\begin{array}{c}\text { Borderline Clinical } \\
\text { Range }\end{array}$ & 4 & Normal Range \\
\hline \multirow{3}{*}{ 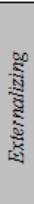 } & $\begin{array}{l}\text { Delinquent } \\
\text { Behavior }\end{array}$ & 5 & 6 & $\begin{array}{c}\text { Borderline Clinical } \\
\text { Range }\end{array}$ & 3 & Normal Range \\
\hline & $\begin{array}{l}\text { Aggressive } \\
\text { Behavior }\end{array}$ & 15 & 22 & Clinical Range & 9 & Normal Range \\
\hline & Total & 11 & 28 & Clinical Range & 12 & $\begin{array}{c}\text { Borderline Clinical } \\
\text { Range }\end{array}$ \\
\hline
\end{tabular}

N's mother's CBCL comparisons showed that after the anger treatment intervention, $\mathrm{N}$ behavioral problems decreased. Before the intervention, $\mathrm{N}$ displayed problematic behaviors that were externalized in the clinical range. However, after the intervention, N's externalizing behavior fell into the borderline clinical range.

N's behavioral problems in the delinquent behavior domain decreased. The pre-intervention score was 6 (in the borderline range), while post-intervention score was 3 (in the normal range). $\mathrm{N}$ no longer displays delinquent behavior, such as swearing.

In addition, N's behavior problems in the aggressive behavior domain decreased. The preintervention score was 22 (in the clinical range), while the post-intervention score was 9 (in the normal range). N's aggressive behavior such as the destruction of personal property, physically attacking others (hitting or kicking), stubbornness, irritability and shouting, had all diminished. Overall, these results indicated that anger treatment using a cognitive behavioral approach was effective at reducing aggressive responses in an adolescent with borderline intelligence.

\section{Discussion and Conclusion}

The evaluation scores above indicated that an anger treatment intervention using a cognitive behavioral approach can reduce aggressive responses in an adolescent with borderline intelligence. This success is evident in the changes in N's expression of anger before and after the intervention. When experiencing anger, $\mathrm{N}$ tended to stay in her room and listen to music to calm herself.

Information obtained from the interview with the mother also indicated that $\mathrm{N}$ responded more appropriately when angry. $\mathrm{N}$ tended to be more easily advised and reprimanded when angry. Before the intervention $\mathrm{N}$ denied the advice the mother provided, but after the intervention she 
was more easily directed when angry. In addition, the mother also reported that $\mathrm{N}$ was better able to overcome her anger, so that it did not appear protracted.

Bhave and Saini (2009) argued that learning how to manage anger can lead individuals to express anger in a positive way. Anger is understood as an emotion with three components; physiological, cognitive, and behavioral (Charlesworth, 2008; Schiraldi \& Kerr, 2002; Novaco \& Howells; in Day et al., 2008). The three components are interconnected, so that interventions that address all three components are considered appropriate for overcoming problematic anger (Rose, West, \& Clifford, 2000). All three components are addressed by the anger treatment intervention using a cognitive behavioral approach.

The cognitive re-structuring component emphasizes focusing participants' attention on the way they think about and see a situation. The arousal reduction component emphasizes methods for overcoming provocative situations and impulsive reactions through regulating breathing, muscle relaxation, and the soothing use of imagination. Meanwhile the behavioral skills component spells out ways to deal with situations that trigger constructive anger and solve problems (Taylor $\&$ Novaco, 2005). In this study, the three components were addressed through gradual exposure, involving simulation of situations that usually triggered anger, using imagination and role playing with the help and direction of the researcher.

The cognitive re-structuring component requests participants to identify and modify certain thought patterns that contribute to aggressive behavior when anger persists. If before the intervention the participant feels that aggressive responses are caused by an inability to control emotions, or the mistakes of others who disturb them; then after the intervention the participant learns to control such emotions, although perhaps very little. In general, participants are encouraged to consider that others' responses that trigger anger were not deliberately intended to disturb them. This change in perspective is obtained through practicing perspective-taking. However, this could only be controlled by participants to the extent of their understanding, and required direction from researchers, so was not applied directly to a real situation.

There was a change in N's intensity of anger, seen from the decreased anger thermometer scores. The decreased intensity of anger experienced was obtained through training in managing arousal symptoms taught during the arousal reduction component. Participants are taught to manage their anger through exercise to regulate breathing, muscle relaxation, and the soothing use of imagination, to decrease the intensity of their anger.

There are several factors that support the success of anger treatment interventions using cognitive behavioral approaches. First, participants' awareness of the problems they have and their desire to change. According to Beck (2011), one of the things that supports the success of a therapy is the clients' motivation to change. During the assessment process, $\mathrm{N}$ stated a desire to overcome her anger problems. $\mathrm{N}$ also realized that her anger was excessive and has a negative impact on her and those around her. 
Second, the material is evaluated and reviewed at the beginning and end of each session. This helps participants to remember and repeat the material that has been taught. During the session, $\mathrm{N}$ did not hesitate to ask questions and said she was confused when using material that she did not understand. Beck (2011) explained that repetition or review is very helpful during the therapy process. For researchers, it assesses whether participants have understood the process; while for participants, it helps to recall the material that has been received.

Third, the intervention's success requires a positive relationship between the therapist researcher and participant. As stated by Taylor and Novaco (2005), to facilitate clients' regulation of their anger, a good relationship between therapists and clients is crucial, because it builds a sense of security and trust. In this study, $\mathrm{N}$ established a good interaction with the researchers, telling stories about herself and her activities at school and at home.

Fourth, participants and parents must be committed to following the entire program, starting at the assessment stage, through to the preparation stage, treatment stage, and program evaluation stage. The participant should attend each session according to a predetermined schedule, three times a week, unless they have other activities at school or important family events. This wellestablished commitment from participants and parents ensures that each session proceeds with a happy feeling until the entire program is completed. Manassis (2009) also stated that positive rapport and participants' trust in researchers motivates them to attend therapy, and this was one factor required for the successful implementation of the intervention program.

Fifth, some material is delivered verbally, some visually in the form of picture illustrations to facilitate participants' understanding of the material. When conducting assessments and evaluations, the use of thermometer images is considered an effective method for measuring participants' anger intensity. The use of these images is considered helpful because it is more concrete, in accordance with the developmental stages of participants, namely adolescents with borderline intelligence. Cognitively, a teenager should have reached the stage of formal operational development. However, adolescents with a borderline level of intelligence usually reach an operational concrete stage only at the age of 10 to 12 years (Masi, Marcheschi, \& Pfanner, 1998).

In addition to factors supporting the implementation of the intervention program, there are also factors that hinder the success of anger treatment programs using cognitive behavioral approaches. One factor is the lack of participants' cooperation in completing the assigned homework tasks. The work of Manassis (2009) supports this. Not wanting to complete the assignments and homework given is likely to undermine the progress of cognitive behavioral therapy.

In this study, the participant did not report the anger she experienced in the anger log exercise sheet on the grounds that there were no situations that made her angry. However, after being further questioned, actually there was a situation that made her angry, but she did not write it down for lazy reasons. In fact, according to Sukholsky et al. (in Cavell \& Malcolm, 2007) 
reluctance to do homework in the form of self-monitoring (anger log) can affect the effectiveness of the program.

When participants are requested to report of event that have triggered their anger before starting the session means the session execution time lasts longer. Some material reported in the anger $\log$ requires thinking ability. In fact, adolescents with borderline intelligence will usually experience limitations when performing tasks that involve analysis (Masi, Marcheschi, \& Pfanner, 1998). Thus, participants need assistance during this process. As stated by Taylor and Novaco (2005), anger log homework should be conducted together with the client's companion. In this study, the mother was judged as less actively involved in assisting the participant to carry out their homework tasks. Mom only occasionally asked $\mathrm{N}$ whether she had done her homework, but did not check what she did.

Another factor inhibiting the success of such intervention programs is the difficulty collecting information about participants' negative thoughts when dealing with situations that trigger anger. The participant with borderline intelligence will not be aware of what she really thinks, but focuses on feelings. The limitations entailed cause a lack of awareness of inner processes, such as thinking about one's own thoughts (Masi, Marcheschi, \& Pfanner, 1998). The skills mastered by such participants typically involve feelings, namely relaxation (imagining a situation that is calming or pleasant and doing an APR) because it is considered easier and more practical. Meanwhile, other skills that involve the process of thinking ("thinking in other ways" and "perspective-taking") are considered very difficult. This is because individuals with borderline intelligence show rigidity in cognitive functions, such as the inability to modify a concept and difficulty considering a problem from a different perspective (Masi, Marcheschi, \& Pfanner, 1998). Repeated training sessions over a long period are required to master such complex cognitive skills.

Therefore, the implementation of the intervention program over eleven sessions provides little opportunity for participants to practice the skills that have been taught, especially those involving the thinking process. In addition, participants do not have an opportunity to practice skills in real-life situations.

This research has several limitations, the first was the measuring instrument used. The measuring instrument in this study was the AESC which assesses four aspects, namely trait anger, anger expression, anger in, and anger control. The four aspects of AESC measure two main components that are the focus of attention during anger treatment using a cognitive behavioral approach, namely arousal reduction and behavioral skills. However, it does not measure cognitive re-structuring. Thus, in this study changes in the client's cognitive re-structuring could only be explained qualitatively, not using the AESC measurement tool.

Another weakness was the implementation of post-intervention follow-up. Post-intervention follow-up is only conducted once, so that the stability of changes that occur in participants is not measured. 


\section{Suggestion}

Based on the results of discussion that has been presented, there are several suggestions that can be made for further research:

a. When doing anger log homework at home, participants should be accompanied by parents or other companions.

b. Provide mMore opportunities for participants to practice the skills that have been taught should be provided, especially those involving the thinking process, for example; by increasing the number of sessions.

c. Providing More opportunities should be provided to practice facing real-life situations, not just imagination or role play.

d. Using other measuring instruments that include a cognitive assessment of participants, so that changes in cognitive structures can be described more comprehensively.

e. Post-intervention more than once, so this study can see the stability of behavior changes in participants.

\section{References}

Achenbach, T.M. (1991). Manual for the child behavior check-list/4-18 and 1991 profile. Burlington, VT: University of Vermont Department of Psychiatry.

Barker, C., Pistrang, N., \& Elliott, R. (2002). Research methods in clinical psychology: An introduction for students and practitioners $\left(2^{\text {nd }}\right.$ ed.). West Sussex: John Wiley \& Sons.

Beck, J.S. (2011). Cognitive behavior therapy: basic and beyond (2nd ed.). New York: The Guilford Press.

Bhave, S. Y. \& Saini, S. (2009). Anger management. New Delhi: Sage Publication India Pvt Ltd.

Blake, C. S., \& Hamrin, V. (2007). Current approaches to the assessment and management of anger and aggression in youth: a review. Journal of Child and Adolescent Psychiatric Nursing, 20(4), 209-221.

Bolanos, C. R., (1998). An evaluation of a social skills training curriculum for anger management in a cronic hospitalized population. (Doctoral Thesis). Available from ProQuest Dissertations and Theses.

Charlesworth, J. R. (2008). Helping adolescents manage anger (ACAPCD-22). Alexandria, VA: American Counseling Association.

Day, A., Howwells, K., Mohr, P., Schall E., \& Gerace, A. (2008). The development of CBT programmes for anger: the role of intervention to promote perspective-taking skill. Behavioral and Cognitive Psychotherapy, 36 (3), 299-312.

Deffenbacher, J. L, Oetting, E. R., \& DiGiuseppe, R. A. (2002). Principles of empirically supported interventions applied to anger management. The Counseling Psychologist, 30(2), 262-280.

Faupel, A., Herrick, E., \& Sharp, P. (2011). Anger Management: A Practical Guide (2nd ed.). Oxon: Routledge.

Fernandez, E. \& Beck, R. (2001). Cognitive-behavioral self-intervention versus self-monitoring of anger: effects on anger frequency, duration, and intensity. Behavioral and Cognitive Psychotherapy 29(3), (pp.345-356).

Golden, B. (2003). Healthy anger: how to help children and teens manage their anger. New York: Oxford University Press.

Jankowska, A. (2016). Towards a framework for psychological resilience in children and adolescents with borderline intellectual functioning. Polish Psychological Bulletin, 47(3), 289-299.

Kail, R. V. (2012). Children and Their Development ( $6^{\text {th }}$ ed.). USA: Pearson.

Karande, S., Kanchan, S., \& Kulkarni, M. (2008). Clinical and psychoeducational profile of children borderline intellectual functioning. Indian journal pediatrics, 75, (.8), 798-800.

Manassis, K. (2009). Cognitive behavioral therapy with children: A guide for the community practitioner. New York: Routledge Taylor \& Francis Group.

Masi, G., Marcheschi, M., \& Pfanner, P. (1998). Adolescents with borderline intellectual functioning: psychopathological risk. Adolescence, 33 (130), 415-424. San Diego: Libra Publisher. 
Miltenberger, R. G. (2016). Behavior modification principles and procedures $\left(6^{\text {th }}\right.$ ed.).. USA: Cengage Learning.

Novaco, R. W., \& Jarvis, K. L. (2002). Brief cognitive behavioral intervention for anger. In Dalam F. W. Bond \& W. Dryden (Eds.), Handbook of brief cognitive behaviour therapy, (pp. 77-100). England: John Wiley \& Sons Ltd.

Novaco, R. W. (2007). Anger dysregulation. In Dalam T. A. Cavell \& K. T. Malcolm (Eds.). Anger, aggression, and intervention for interpersonal violence, (pp. 3-54). New Jersey: Lawrence Erlbaum Associates, Inc.

Papalia, D. E., Olds, S. W., \& Feldman, R. D. (2007). Human development (10 ${ }^{\text {th }}$ ed.). New York: McGraw Hill.

Rose, J., West, C., \& Clifford, D. (2000). Group intervention for anger in people with intellectual disabilities. Research in developmental disabilities, 21 (3), 171-181. Elsevier Science Ltd.

Schiraldi, G. R., \& Kerr, M. H. (2002). The anger management sourcebook. USA: McGraw-Hill.

Shaffer, D. R. (2009). Social and personality development ( $6^{\text {th }}$ ed.). USA: Wadsworth.

Steele, R. G., Legerski, J. P., Nelson, T. D., Phipps, S. (2009). The anger expression scale for children: Initial validity among health children and children with cancer. Journal of Pediatric Psychology, 34(1), 51-62.

Sudhir, P. M. (2015). Cognitive behavior therapy with adolescents. In Dalam M. Mehta \& R. Sagar (Eds.). A practical approach to cognitive behaviour therapy for adolescents (pp. 21-42). New Delhi: Springer India.

Taylor, J. L., \& Novaco, R. W. (2005). Anger treatment for people with developmental disabilities; A theory, evidence and manual based approach. England: John Wiley \& Sons Ltd.

Taylor, J. L., Novaco, R. W., Gillmer, B. T., Robertson, A., \& Thorne, I. (2005). Individual cognitive-behavioural anger treatment for people with mild-borderline intellectual disabilities and histories of aggression: A controlled trial. British Journal of Clinical Psychology, 44 (3), 367-382.

Valizadeh, S., Davaji, R. B. O. \& Nikamal, M. (2010). The effectiveness of anger management skills training on reduction of aggression in adolescents. Procedia - social and behavioral sciences, 5, 1195-1199.

Westbrook, D., Kennerley, H., \& Kirk, J. (2007). An introduction to cognitive behaviour therapy, skills and application. England: Sage Publication. 